\title{
Mortality of Patients Infected by COVID-19 with and without Deep-Vein Thrombosis
}

\author{
Jose Maria Pereira de Godoy ${ }^{1, *(\mathbb{C}, \text { Gleison Juliano da Silva Russeff }}{ }^{2}$, Carolina Hungaro Costa ${ }^{2}$, \\ Debora Yuri Sato ${ }^{2}$, Desirée Franccini Del Frari Silva ${ }^{2}$, Maria de Fatima Guerreiro Godoy ${ }^{3}$ (i), \\ Henrique Jose Pereira de Godoy ${ }^{4}$ and Paulo César Espada ${ }^{5}$
}

1 Cardiovascular Surgery Department, Sao Jose do Rio Preto School of Medicine (FAMERP), Undergraduate Medicine Course and Stricto Sensu Postgraduate Course (FAMERP) and CNPq (National Council for Research and Development), São Jose do Rio Preto 15025120, Brazil

2 Vascular Surgery Echography Service, Hospital Affiliated with Sao Jose do Rio Preto School of Medicine (FAMERP), São Jose do Rio Preto 15025120, Brazil; girusseff@hotmail.com (G.J.d.S.R.); carolinacunha1@gmail.com (C.H.C.); deboraysato@hotmail.com (D.Y.S.); dfrancinni@yahoo.com.br (D.F.D.F.S.)

3 Stricto Sensu Postgraduate Program, Sao Jose do Rio Preto School of Medicine (FAMERP), Research Group at Godoy Clinic, Sao Jose do Rio Preto 15025120, Brazil; mfggodoy@gmail.com

4 Department of General Surgery, Sao Jose do Rio Preto School of Medicine (FAMERP), São Jose do Rio Preto 15025120, Brazil; henriquegodoy95@gmail.com

5 Trauma Surgery, Sao Jose do Rio Preto School of Medicine (FAMERP), São Jose do Rio Preto 15025120, Brazil; pespada@terra.com.br

* Correspondence: godoyjmp@gmail.com; Tel./Fax: +55-1732326362

Citation: Pereira de Godoy, J.M.; Russeff, G.J.d.S.; Costa, C.H.; Sato, D.Y.; Silva, D.F.D.F.; Guerreiro Godoy, M.d.F.; Pereira de Godoy, H.J.; Espada, P.C. Mortality of Patients Infected by COVID-19 with and without Deep-Vein Thrombosis. Medicines 2021, 8, 75. https:// doi.org/10.3390/medicines 8120075

Academic Editor: Akram Zaaqoq

Received: 16 October 2021

Accepted: 24 November 2021

Published: 29 November 2021

Publisher's Note: MDPI stays neutral with regard to jurisdictional claims in published maps and institutional affiliations.

Copyright: (c) 2021 by the authors. Licensee MDPI, Basel, Switzerland. This article is an open access article distributed under the terms and conditions of the Creative Commons Attribution (CC BY) license (https:// creativecommons.org/licenses/by/ $4.0 /)$.
Abstract: Background: Current evidence points to a state of hypercoagulability (consequence of hyperinflammation) as an important pathogenic mechanism that contributes to the increase in mortality in cases of COVID-19. The aim of the present study was to investigate the influence of deep-vein thrombosis on mortality patient's infected with SARS-CoV-2. Method: A clinical trial was conducted involving 200 consecutive patients with COVID-19-100 patients who were positive for deep-vein thrombosis (venous Doppler ultrasound) and 100 who were negative for deep-vein thrombosis at a public hospital. Results: The mortality rate was $67 \%$ in the group positive for DVT and $31 \%$ in the group negative for DVT. Conclusion: Deep-vein thrombosis is associated with an increase in mortality in patients with COVID-19 and failures can occur with conventional prophylaxis for deep-vein thrombosis.

Keywords: COVID-19; mortality; deep-vein thrombosis; Doppler; ultrasound

\section{Introduction}

Current evidence points to a state of hypercoagulability (a consequence of hyperinflammation) as an important pathogenic mechanism that contributes to the increase in mortality in cases of COVID-19. This theory is supported by reports of high inflammatory markers and clotting as well as a correlation between high interleukin-6 (IL-6) levels and fibrinogen. The anti-inflammatories with anticoagulants could decrease thrombotic events and related fatal consequences [1-4].

An autopsy study found that $81 \%$ of patients with COVID-19 as the main cause of death exhibited thrombotic phenomena in the lungs. The extrapulmonary thrombotic events were ischemic stroke $(\mathrm{N}, \%=4 ; 3.95)$, acute myocardial infarction $(\mathrm{N}, \%=3 ; 2.94)$, and critical lower limb ischemia $(\mathrm{N}, \%=1 ; 0.98)$ [5]. Another study showed that autopsy revealed deep-vein thrombosis in $(58 \%)$ in whom venous thromboembolism was not suspected before death [6].

The underlying mechanisms proposed for these severe manifestations involve immunological dysregulation, including an antiphospholipid syndrome-like state, activation 
of the complement system, viral dissemination with direct systemic endothelial infection, viral RNAemia with immunothrombosis, activation of the clotting pathway mediated by hypoxemia, and immobility [7-10]. Antiphospholipid syndrome is associated with arterial and venous thrombosis, but other causes of congenital thrombophilia should be considered, such as the deficiencies in C protein, $\mathrm{S}$ protein, antithrombin III, etc. [11,12]. Arterial and venous thrombotic conditions are among the most serious complications of COVID19 , and the diagnosis of these conditions using Doppler ultrasound is the main form of evaluation of the extremities [13,14]. Thromboprophylaxis is mainly performed with lowmolecular-weight heparin (LMWH) and, in some specific patients, with unfractionated heparin (UFH) [15].

The aim of the present study was to investigate the influence of deep-vein thrombosis on mortality patient's infected with SARS-CoV-2.

\section{Methods}

\subsection{Patients and Setting}

A total of 200 consecutive patients with COVID-19 (100 with DVT and 100 without DVT) were evaluated at the public hospital affiliated with the São Jose do Rio Preto School of Medicine (SP, Brazil) between March 2020 and May 2021. Deep-vein thrombosis (DVT) was investigated using venous Doppler ultrasound.

\subsection{Design}

A clinical trial was conducted involving 100 patients with COVID-19 positive for DVT (venous Doppler ultrasound) and 100 negative for DVT. Patients negative for COVID19 and those with inconclusive exams were excluded. The difference in mortality was analyzed using Fisher's exact test.

\subsection{Inclusion and Exclusion Criteria}

All patients with COVID-19 submitted to venous Doppler ultrasound at the public hospital affiliated with the São Jose do Rio Preto School of Medicine with a suspicion of DVT were included in the study. Patients negative for COVID-19 and those with inconclusive exams were excluded.

\subsection{Ethical Considerations}

This study received approval from the institutional review board of the São Jose do Rio Preto School of Medicine, SP, Brazil \#4.720.521. All participants signed a statement of informed consent.

\subsection{Statistical Treatment}

Descriptive statistics were performed on the data and comparisons were made using Fisher's exact test, considering an alpha error of $5 \%$.

\subsection{Selection of Patients}

Consecutive patients with COVID-19 submitted to venous Doppler ultrasound until reaching 100 positive for DVT and 100 negative for DVT.

\subsection{Development}

The São Jose do Rio Preto Hospital had 5559 patients with COVID-19 during the study: $3706(71.8 \%)$ in the medical wards and $1453(28.1 \%)$ in the intensive care units. More than 200 patients in the ICUs had a suspicion of DVT and were sent for bilateral venous Doppler ultrasound of the lower limbs. These patients were subsequently divided into two groups: 100 positive for DVT and 100 negative for DVT. The mean D-dimer results, age group, and mortality were evaluated in each group. The data were entered into an Excel table and analyzed descriptively. Comparisons between groups were performed using Fisher's exact test, considering a $5 \%$ alpha error. 


\section{Results}

Mean age was $55.58 \pm 12.58$ years in the group positive for DVT and $58.61 \pm 14.2$ years in the group negative for DVT. This difference was not statistically significant $(p=0.1$, paired $t$-test). The mortality rate was $67 \%$ in the group positive for DVT and $31 \%$ in the group negative for DVT. This difference was statistically significant $(p=0.0001$, Fisher's exact test) (Table 1). The mean D-dimer level was $11.9 \pm 7.15 \mathrm{um}$ in the group with DVT and $4.97 \pm 5.3 \mathrm{um}$ in the group without DVT. The median difference was 10.25 (CI: 8.51 to 13.46) and was statistically significant ( $p<0.0001$, Mann-Whitney U test) (Figure 1 ).

Table 1. Descriptive statistics of patients with and without deep-vein thrombosis.

\begin{tabular}{ccc}
\hline Variables & Without DVT & With DVT \\
\hline Valid data & 100 & 100 \\
Mean & 3.59 & 7.47 \\
Standard deviation & 3.58 & 28.94 \\
Median & 2.33 & 3.3 \\
\hline
\end{tabular}

\section{With DTV-D-dimer}

Without DTV-D-dimer

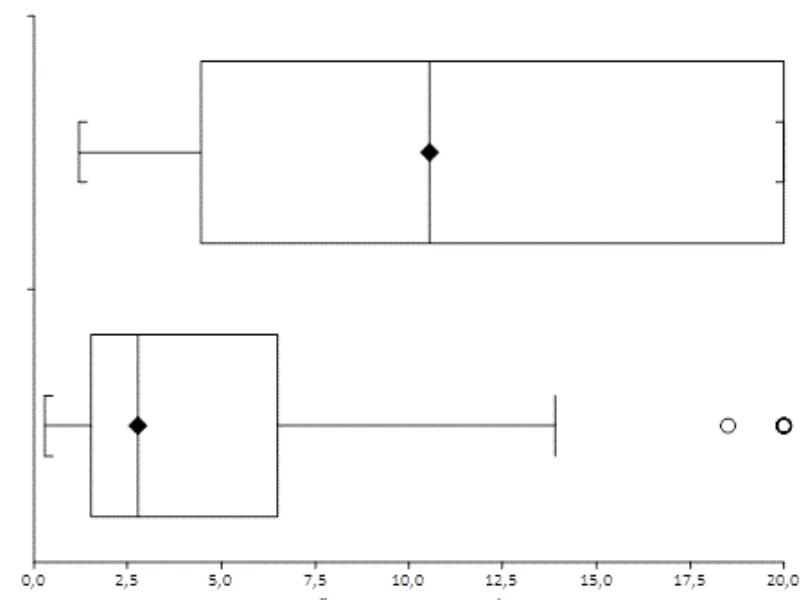

Figure 1. Median D-dimer levels and interquartile ranges in patients with and without deepvein thrombosis.

\section{Discussion}

The present study points to deep-vein thrombosis (DVT) as one of the main complications of SARS-CoV-2 related to mortality. The mortality rate among the patients with DVT was more than double that found in the group without DVT. The patients were from a single teaching school, where the conduct in the intensive care units is uniform and all patients received injectable antithrombotic prophylaxis. This prophylactic procedure was based on changes in D-dimer levels and clinical aspects. The literature offers several studies reporting pulmonary thrombosis in approximately 80\% of COVID-19-related deaths [11], but no previous study has evaluated the influence of DVT.

One of the characteristics of COVID-19 is the involvement of multiple sites of microand macro-thrombosis in the lungs. Venous thrombotic events of the lower limbs are also seen [16-18]. However, these details are not part of the present study. The characteristics of thrombotic events differ from those found in patients without COVID-19. Therefore, a novel presentation characteristic of thrombotic events is seen in this pandemic. A study has shown that the mortality rate was significantly higher $(16.0 \%)$ in patients with thrombosis than in those without thrombosis (7.9\%) [19]. The vast majority of individuals who died directly from SARS-CoV-2 infection were of advanced age and had multiple comorbidities [20].

One hypothesis for the increase in mortality is the greater occurrence of extrapulmonary thrombosis. Micro- and macro-thrombotic events can affect the entire organism, thereby increasing the sequelae of this physiopathological process [17]. The D-dimer level 
practically doubles in comparison to patients without DVT, suggesting a greater volume of lysis due to the thrombotic process.

Some patients without DVT had high D-dimer levels, suggesting thrombotic involvement in other parts of the body, such as the upper limbs and abdomen. Arterial thrombotic events have been seen at our service, but with less frequency. The early diagnosis of a thrombotic event is fundamental so that these patients can receive adequate treatment for DVT.

While prophylaxis for DVT is fundamental, failures in prevention have occurred even when using Clexane 40 um every $12 \mathrm{~h}$, suggesting considerable viral aggression to the vascular system.

\section{Conclusions}

Deep-vein thrombosis is associated with an increase in mortality in patients with COVID-19, and failures can occur with conventional prophylaxis for deep-vein thrombosis.

Author Contributions: Design: J.M.P.d.G., G.J.d.S.R., C.H.C., D.Y.S., D.F.D.F.S., M.d.F.G.G., H.J.P.d.G. and P.C.E.; analysis and interpretation of data: J.M.P.d.G., G.J.d.S.R., C.H.C., D.Y.S., D.F.D.F.S., M.d.F.G.G., H.J.P.d.G. and P.C.E.; data collection: J.M.P.d.G., G.J.d.S.R., C.H.C., D.Y.S., D.F.D.F.S., M.d.F.G.G., H.J.P.d.G. and P.C.E.; article writing: J.M.P.d.G., G.J.d.S.R., C.H.C., D.Y.S., D.F.D.F.S., M.d.F.G.G., H.J.P.d.G. and P.C.E.; critical review of text: J.M.P.d.G. G.J.d.S.R., C.H.C., D.Y.S., D.F.D.F.S., M.d.F.G.G., H.J.P.d.G. and P.C.E.; statistical analysis: J.M.P.d.G., G.J.d.S.R., C.H.C., D.Y.S., D.F.D.F.S., M.d.F.G.G., H.J.P.d.G. and P.C.E.; overall responsibility for study: J.M.P.d.G., G.J.d.S.R., C.H.C., D.Y.S., D.F.D.F.S., M.d.F.G.G., H.J.P.d.G. and P.C.E. All authors have read and agreed to the published version of the manuscript.

Funding: This research received no external funding.

Institutional Review Board Statement: Review board of the São Jose do Rio Preto School of Medicine, SP, Brazil \#4.720.521.

Informed Consent Statement: All participants signed a statement of informed consent.

Data Availability Statement: The data used to support the findings of this study are included within the article.

Conflicts of Interest: The authors declare no conflict of interest.

\section{References}

1. Wu, M.A.; Colombo, R.; Arquati, M.; Ippolito, S.; Taino, A.; Ruggiero, D.; Tonelli, F.; Trombetta, L.; Facchinetti, P.; Glielmo, P.; et al. Clinical-radiological correlations in COVID-19-related venous thromboembolism: Preliminary results from a multidisciplinary study. Int. J. Clin. Pract. 2021, 75, e14370. [CrossRef] [PubMed]

2. Parums, D.V. Editorial: Multisystem Inflammatory Syndrome in Adults (MIS-A) and the Spectrum of COVID-19. Med. Sci. Monit. 2021, 27, e935005. [CrossRef] [PubMed]

3. Tufan, Z.K.; Kayaaslan, B.; Mer, M. COVID-19 and SEPSIS. Turk. J. Med. Sci. 2021, 51, 1-11. [CrossRef]

4. Rad, F.; Dabbagh, A.; Dorgalaleh, A.; Biswas, A. The Relationship between Inflammatory Cytokines and Coagulopathy in Patients with COVID-19. J. Clin. Med. 2021, 10, 2020. [CrossRef] [PubMed]

5. Stark, K.; Massberg, S. Interplay between inflammation and thrombosis in cardiovascular pathology. Nat. Rev. Cardiol. 2021, 18, 666-682. [CrossRef] [PubMed]

6. Wichmann, D.; Sperhake, J.P.; Lütgehetmann, M.; Steurer, S.; Edler, C.; Heinemann, A.; Heinrich, F.; Mushumba, H.; Kniep, I.; Schröder, A.S.; et al. Autopsy Findings and Venous Thromboembolism in Patients With COVID-19: A Prospective Cohort Study. Ann. Intern. Med. 2020, 173, 1030. [CrossRef]

7. Nicolai, L.; Leunig, A.; Brambs, S.; Kaiser, R.; Weinberger, T.; Weigand, M.; Muenchhoff, M.; Hellmuth, J.C.; Ledderose, S.; Schulz, H.; et al. Immunothrombotic Dysregulation in COVID-19 Pneumonia Is Associated With Respiratory Failure and Coagulopathy. Circulation 2020, 142, 1176-1189. [CrossRef] [PubMed]

8. García-Ceberino, P.M.; Faro-Míguez, N.; Beltrán-Ávila, F.J; Fernández-Reyes, D.; Gallardo-Muñoz, I.; Guirao-Arrabal, E. Point of care ultrasound (POCUS) in diagnosis of proximal deep vein thrombosis among COVID-19 hospitalized patients with a high rate of low molecular weight heparin prophylaxis. Med. Clin. 2021, 157, 172-175. [CrossRef] [PubMed]

9. Longchamp, G.; Manzocchi-Besson, S.; Longchamp, A.; Righini, M.; Robert-Ebadi, H.; Blondon, M. Proximal deep vein thrombosis and pulmonary embolism in COVID-19 patients: A systematic review and meta-analysis. Thromb. J. 2021, 19, 12. [CrossRef] [PubMed] 
10. Lapébie, F.-X.; Minville, V.; Ribes, A.; Combis, B.; Thery, A.; Geeraerts, T.; Silva, S.; Bura-Rivière, A.; Vardon-Bounes, F. Systematic Screening for Deep Vein Thrombosis in Critically Ill Inpatients With COVID-19: Impact on the Incidence of Venous Thromboembolism. Front. Med. 2021, 7, 624808. [CrossRef] [PubMed]

11. de Godoy, J.M.P.; de Godoy, M.F.; Braile, D.M. Recurrent Thrombosis in Patients with Deep Vein Thrombosis and/or Venous Thromboembolism Associated with Anticardiolipin Antibodies. Angiology 2006, 57, 79-83. [CrossRef]

12. de Godoy, J.M.P.; Braile, D.M. Protein S Deficiency in Repetitive Superficial Thrombophlebitis. Clin. Appl. Thromb. 2003, 9, 61-62. [CrossRef]

13. de Godoy, J.M.; Russeff, G.J.; Santos, H.A.; de Godoy, A.C. Stenosis of large lower limb arteries in a teenager after COVID-19 infection. Med. Sci. 2021, 25, 2680-2684.

14. Romanova, E.S.; Vasilyev, V.V.; Startseva, G.; Karev, V.; Rybakova, M.G.; Platonov, P.G. Cause of death based on systematic post-mortem studies in patients with positive SARS-CoV-2 tissue PCR during the COVID-19 pandemic. J. Intern. Med. 2021, 290, 655-665. [CrossRef]

15. Mansory, E.M.; Srigunapalan, S.; Lazo-Langner, A. Venous Thromboembolism in Hospitalized Critical and Noncritical COVID-19 Patients: A Systematic Review and Meta-analysis. TH Open 2021, 5, e286-e294. [CrossRef] [PubMed]

16. Hsu, A.; Ohnigian, S.; Chang, A.; Liu, Y.; Zayac, A.S.; Olszewski, A.J.; Reagan, J.L. Thrombosis in COVID-19: A Narrative Review of Current Literature and Inpatient Management. Rhode Isl. Med. J. 2021, 104, 14-19.

17. Fahmy, O.H.; Daas, F.M.; Salunkhe, V.; Petrey, J.L.; Cosar, E.F.; Ramirez, J.; Akca, O. Is Microthrombosis the Main Pathology in Coronavirus Disease 2019 Severity?-A Systematic Review of the Postmortem Pathologic Findings. Crit. Care Explor. 2021, 3, e0427. [CrossRef]

18. Case, B.C.; Abramowitz, J.; Shea, C.; Rappaport, H.; Medranda, G.A.; Yerasi, C.; Forrestal, B.J.; Chezar-Azerrad, C.; Zhang, C.; Satler, L.F; et al. Comparison of Outcomes in Patients With COVID-19 and Thrombosis Versus Those Without Thrombosis. Am. J. Cardiol. 2021, 160, 106-111. [CrossRef]

19. Fitzek, A.; Schädler, J.; Dietz, E.; Ron, A.; Gerling, M.; Kammal, A.L.; Lohner, L.; Falck, C.; Möbius, D.; Goebels, H.; et al. Prospective postmortem evaluation of 735 consecutive SARS-CoV-2-associated death cases. Sci. Rep. 2021, 11, 19342. [CrossRef] [PubMed]

20. Cauchie, P.; Piagnerelli, M. What Do We Know about Thromboprophylaxis and Its Monitoring in Critically Ill Patients? Biomedicines 2021, 9, 864. [CrossRef] 